\title{
Upconversion Luminescence and Photodegradation Performances of Pr Doped $\mathrm{Y}_{2} \mathrm{SiO}_{5}$ Nanomaterials
}

\author{
Yi Yang, ${ }^{1,2}$ Cheng Liu, ${ }^{1}$ Ping Mao, ${ }^{1,2}$ and Lian-Jun Wang ${ }^{1,2}$ \\ ${ }^{1}$ School of Environmental and Biological Engineering, Nanjing University of Science and Technology, Nanjing 210094, China \\ ${ }^{2}$ Lianyungang Institute, Nanjing University of Science and Technology, Lianyungang 222006, China \\ Correspondence should be addressed to Yi Yang; yyi301@163.com
}

Received 12 July 2013; Accepted 2 August 2013

Academic Editor: Guangyu Zhao

Copyright (c) 2013 Yi Yang et al. This is an open access article distributed under the Creative Commons Attribution License, which permits unrestricted use, distribution, and reproduction in any medium, provided the original work is properly cited.

\begin{abstract}
Yttrium silicates $\mathrm{Y}_{2} \mathrm{SiO}_{5}$ upconversion nanomaterials with different doping concentrations of praseodymium ion Pr are prepared by using a sol-gel method. X-ray diffractometer, SEM, Fourier transform infrared spectrometer, and fluorescence spectrometer have been employed to test the crystal structure and upconversion luminescence performances. The results indicate that samples calcined higher than $950^{\circ} \mathrm{C}$ present fine crystal structures, of which Si-O-Si band at $757-1048 \mathrm{~cm}^{-1}$ splits into three fine peaks. The crystal size of the samples calcined at $950^{\circ} \mathrm{C}$ and $1000^{\circ} \mathrm{C}$ is $29.1 \mathrm{~nm}$ and $66.7 \mathrm{~nm}$, respectively. The luminescence intensities of the samples are increasing at first and then decreasing, with the increasing of the doping concentrations of $0.47 \%, 0.77 \%, 0.96 \%, 2.95 \%$, and 4.93\%. Nanomaterial sample doped $0.96 \%$ Pr emits the highest upconversion luminescence intensity of $6.43 \times 10^{6} \mathrm{cps}$ and shows the best photodegradation performance for nitrobenzene wastewater. It demonstrates that too much of Pr doping concentration would result in quenching of the fluorescence. Nevertheless, as the degradation time expands, sample doped 0.96\% Pr shows much faster increasing of photodegradation rate than samples of other doping concentrations and reaches to a high photodegradation rate of $97.14 \%$ in 6 hours for $10 \mathrm{mg} / \mathrm{L}$ nitrobenzene wastewater.
\end{abstract}

\section{Introduction}

Upconversion nanomaterials are known for its efficient emission of ultraviolet fluorescence under the exciting visible light [1]. It has been extensively studied since mid-1960s and widely applied in many areas [2-4]. The emission of short wavelength light excited by long wavelength light is called antistokes luminescence, namely, upconversion luminescence. Upconversion nanomaterials and upconversion luminescence can be widely used in the degradation of organic pollutants in environmental governance [5] and the killing of harmful bacteria in medical treatment or biological areas [68], because of the ultraviolet light emitted in the upconversion processes. The upconversion nanomaterials, which is differ from ultraviolet lamp, can be excited by visible light, such as sun light, instead of electricity.

In the past decades, high-quality rare earth-doped upconversion nanomaterials have been successfully synthesized with the rapid development of nanotechnology and are becoming more prominent in biological and environmental sciences [9-11]. However, till now, the low luminescence efficiency is still one of the main limiting factors for upconversion materials. A suitable host material with lower phonon energy is one of the most important factors to obtain high upconversion luminescence efficiency. Up to now, host materials, including fluoride, chloride, and bromide, have been shown to enhance upconversion luminescence intensity. As a substrate for upconversion materials, yttrium silicates $\mathrm{Y}_{2} \mathrm{SiO}_{5}$ show high thermal stability, good optical performance, simple manufacture process, and has been widely used in fluorescent technique, optical information storage, and anticounterfeit technology [12].

To get the highest upconversion luminescence efficiency, another critical factor is doping with other ions to occupy or replace the ions in the host material [13-15]. In the molecular geometry of yttrium silicates $\mathrm{Y}_{2} \mathrm{SiO}_{5}$, yttrium ion $\mathrm{Y}$ is located on two different positions and its corresponding coordinate numbers are 7 and 9 in X1 molecular configuration, while 6 and 7 in X2 molecular configuration [16]. The particular geometry leads to a possible replace of $\mathrm{Y}$ by other element 
ions. Praseodymium ion has a similar ionic radius with $\mathrm{Y}$ ion, but more suitable energy levels and longer excited state lifetimes than Y. This lead to the transition of Pr to a lower energy band after absorbing two photons continuously. As a result, higher energy photons could be emitted. Therefore, Praseodymium ion is a potential doping element ion for the $\mathrm{Y}_{2} \mathrm{SiO}_{5}$ system to obtain high energy photons and excellent upconversion performances.

Besides the host materials and doping ions, the synthetic methods are also critical for the high quality upconversion nanomaterials to obtain high luminescence efficiency. The synthesis methods are usually phase-based processes. So far, three kinds of methods are commonly used to synthesize upconversion nanomaterials, including thermal decomposition [17-19], hydrothermal synthesis [20, 21], and ionic liquids-based synthesis [22]. In addition, sol-gel method has potential for synthesizing high quality upconversion nanomaterials of high luminescence efficiency and usually used as the first choice to doping ions since it provides a way of mixing in molecular level of the reactants $[23,24]$, which has also been used in this study.

Many researches focused on the optical properties, luminescence properties, and fluorescence quenching mechanisms of $\mathrm{Pr}$ doped $\mathrm{Y}_{2} \mathrm{SiO}_{5}$ crystals [25-27]. Also, a number of studies report the application of $\mathrm{Pr}$ doped $\mathrm{Y}_{2} \mathrm{SiO}_{5}$ nanomaterials in biological, medical, sensing, optical areas, and so on $[2,3,5-8]$. In particular, the upconversion nanomaterials unique property of emitting visible light under NIR irradiation makes them a suitable candidate both for in vivo and in vitro bioimaging $[28,29]$. However, the research and application of $\mathrm{Pr}$ doped $\mathrm{Y}_{2} \mathrm{SiO}_{5}$ nanomaterials on environment or pollutants degradation are seldom reported. In this study, nitrobenzene wastewater, which is from a TNT factory, has been used as the target pollutant to test the photodegradation performances of the prepared $\mathrm{Pr}(\mathrm{III})$ doped $\mathrm{Y}_{2} \mathrm{SiO}_{5}$ upconversion nanomaterials.

\section{Materials and Methods}

Praseodymium ion $\mathrm{Pr}(\mathrm{III})$, doped $\mathrm{Y}_{2} \mathrm{SiO}_{5}$ upconversion nanomaterials were prepared by using a sol-gel method. First, $0.1 \mathrm{~mol} / \mathrm{L}$ praseodymium nitrate solution was added into the mixture $\left(1: 1\right.$, vol) of $\mathrm{HNO}_{3}$ and $\mathrm{H}_{2} \mathrm{O}$ dissolved $0.663 \mathrm{~g} \mathrm{Y}_{2} \mathrm{O}_{3}$. Heating was followed until the solution becomes a viscous mixture. A number of crystals were seed out after cooling down. The crystal was collected and dissolved in ethanol. Tetraethyl orthosilicate (TEOS) was added and mixed with the ethanol solution of the crystals. The obtained mixture was put into a water bath of $70^{\circ} \mathrm{C}$ until a gel was formed. The gel was dried in an oven of $104^{\circ} \mathrm{C}$ and then grinded into powder. At last, the powder was calcined at a temperature oR $900^{\circ} \mathrm{C}$, $950^{\circ} \mathrm{C}$, and $1000^{\circ} \mathrm{C}$ for $3 \mathrm{~h}$ in a muffle furnace to get the final product of $\mathrm{Pr}$ (III) doped $\mathrm{Y}_{2} \mathrm{SiO}_{5}$ upconversion nanomaterials. The $\operatorname{Pr}$ (III) doping concentrations, 0.47\%, 0.77\%, 0.96\%, $2.95 \%$, and $4.93 \%$, which were confirmed by using inductively coupled plasma (ICP) spectrometer, were adjusted by changing the adding volume of the $0.1 \mathrm{~mol} / \mathrm{L}$ praseodymium nitrate solution at the first stage.

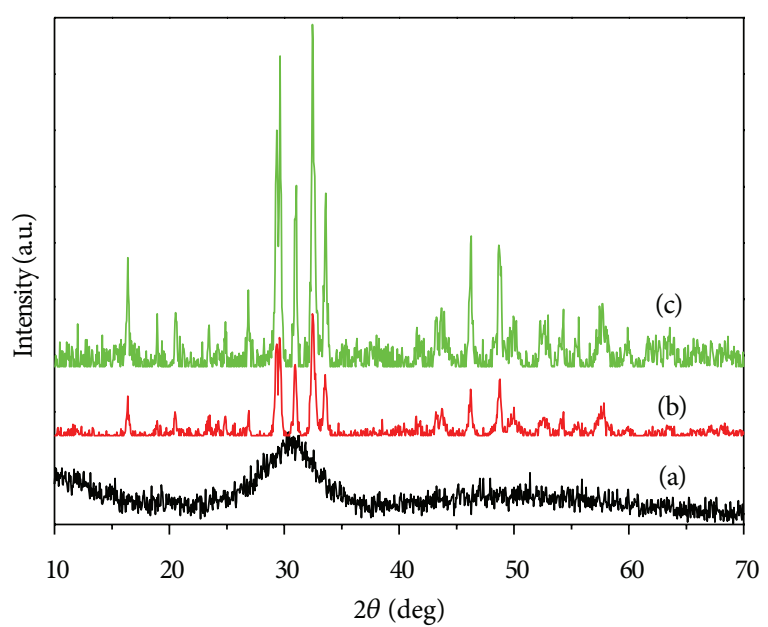

FIGURE 1: XRD patterns of $\operatorname{Pr}(\mathrm{III})$ doped samples calcined at different temperatures: (a) $900^{\circ} \mathrm{C}$, (b) $950^{\circ} \mathrm{C}$, (c) $1000^{\circ} \mathrm{C}$.

X-ray diffractometer (D8 Advance, Bruker Corporation, German) was used to characterize the crystal form of the samples. A scanning electron microscopy (Hitachi S4800, SEM, Japan) was employed to characterize the particle size of the samples. Fourier transform infrared spectrometer (FTIR, MB154S, ABB BOMEN Corporation, Canada) was employed to check the crystal and groups of samples. The upconversion luminescence of the nanomaterials was tested by using a fluorescence spectrometer (FL3-TCSPC, Horiba Jobin Yvon Corporation, France). The exciting parameters were selected as $425 \mathrm{~nm}$ of the excitation wavelength, $370 \mathrm{~nm}$ of the optical filters, and $2 \mathrm{~nm}$ of the slit.

Nitrobenzene wastewater, $10 \mathrm{mg} / \mathrm{L}$, which was from a TNT factory, was used as a target pollutant to test the photodegradation performances of the prepared $\operatorname{Pr}$ (III) doped $\mathrm{Y}_{2} \mathrm{SiO}_{5}$ upconversion nanomaterials. Filament lamp, $52 \mathrm{~W}$, was used as the exciting light source for the upconversion nanomaterials. The treatment time was lasting for $1 \mathrm{~h}$ to $6.5 \mathrm{~h}$. The degradation rate of nitrobenzene was tested by comparing the ultraviolet absorption values to the original value of the wastewater. The ultraviolet absorption values were tested by using an ultraviolet-visible spectrophotometer. The relationship of the nitrobenzene concentrations $(x)$, in the range of $0-15 \mathrm{mg} / \mathrm{L}$, with the ultraviolet absorption values $(y)$, was determined by a linear equation: $y=0.072 x+0.012$, with a correlation $R^{2}$ of 0.9987 .

\section{Results and Discussion}

3.1. Heat Treatment on the Crystal of Upconversion Nanomaterials. The heat treatment temperature is an important parameter for the crystal structure and crystal size of many kinds of nanomaterials, as well as upconversion nanomaterials. Figure 1 shows the XRD patterns of $\operatorname{Pr}$ (III) doped samples at the heat treatment temperature of $900^{\circ} \mathrm{C}, 950^{\circ} \mathrm{C}$, and $1000^{\circ} \mathrm{C}$.

Without obvious diffraction peak appears on the XRD pattern of sample calcined at $900^{\circ} \mathrm{C}$, except for a bread curve at the 2-theta angle about $30^{\circ}$. It means that $\mathrm{Y}_{2} \mathrm{SiO}_{5}$ under 


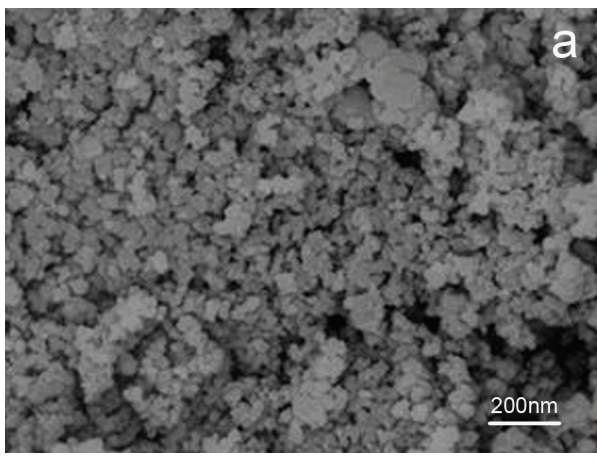

(a)

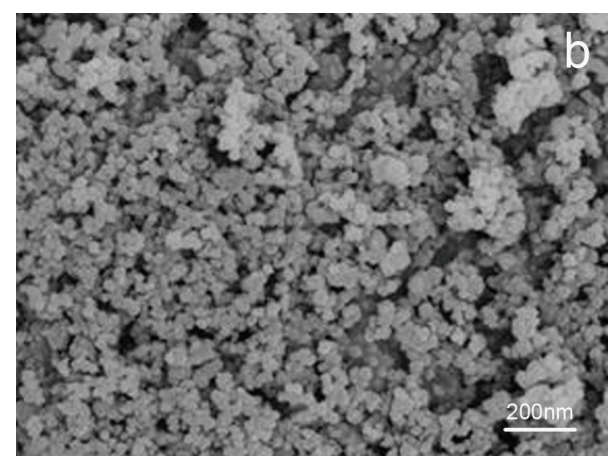

(b)

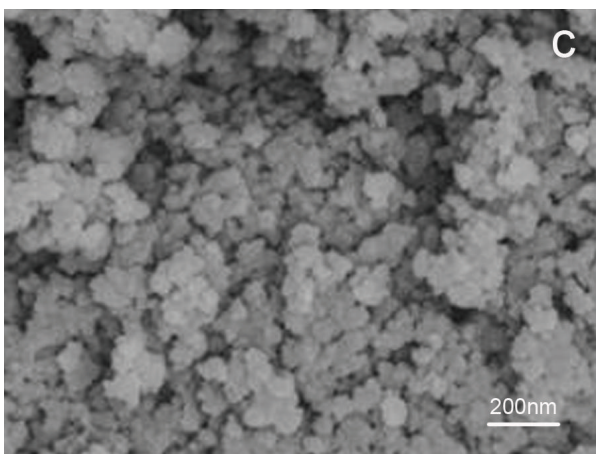

(c)

Figure 2: SEM images of $\operatorname{Pr}(\mathrm{III})$ doped samples calcined at different temperature (a) $900^{\circ} \mathrm{C}$; (b) $950^{\circ} \mathrm{C}$; (c) $1000^{\circ} \mathrm{C}$.

the heat treatment temperature of $900^{\circ} \mathrm{C}$ is amorphous. Meanwhile, a higher heat treatment temperature of $950^{\circ} \mathrm{C}$ or $1000^{\circ} \mathrm{C}$ leads to good crystal forms of the $\operatorname{Pr}(\mathrm{III})$ doped $\mathrm{Y}_{2} \mathrm{SiO}_{5}$ upconversion nanomaterials, of which diffraction peak positions show high consistency with that of $\mathrm{Xl}^{-} \mathrm{Y}_{2} \mathrm{SiO}_{5}$ phase [30]. The temperature is further lower than the report postanneal temperature $1373 \mathrm{~K}$ for $\mathrm{Xl}_{1} \mathrm{Y}_{2} \mathrm{SiO}_{5}$ phase [30]. However, sample calcined at $1000^{\circ} \mathrm{C}$ shows much higher diffraction peaks than that of sample calcined at $950^{\circ} \mathrm{C}$. This phenomenon states a conclusion that the crystal size of the later is smaller than that of the former, $29.1 \mathrm{~nm}$ and $66.7 \mathrm{~nm}$ at $2 \theta$ angle $32.67^{\circ}$, respectively, which are calculated by the Scherrer equation: $D=K \lambda /(\beta \cos \theta)$, where $D$ is the crystal size (nm); $K$ is 0.89 , the Scherrer constant; $\beta$ is the full width at half maximum (FWHM) of the main diffraction peaks $(\mathrm{rad}) ; \theta$ is the diffraction angle which the diffraction peaks located $\left({ }^{\circ}\right) ; \lambda$ is $0.154056 \mathrm{~nm}$, the $\mathrm{X}$-ray wavelength.

It indicates that the crystal structure transition temperature of $\mathrm{Pr}$ (III) doped X1 pattern $\mathrm{Y}_{2} \mathrm{SiO}_{5}$ is about $950^{\circ} \mathrm{C}$, heat treatment temperature higher than $950^{\circ} \mathrm{C}$ is not good for the forming of small crystal size for the materials.

The particle size of the samples characterized by a scanning electron microscopy also shows high dependence on the heat treatment temperature, as shown in Figure 2. With the increasing of heat treatment temperature, the particle sizes of the samples are increasing gradually, $42 \mathrm{~nm}, 55 \mathrm{~nm}$, and $96 \mathrm{~nm}$ for the treatment temperature of $900^{\circ} \mathrm{C}, 950^{\circ} \mathrm{C}$, and $1000^{\circ} \mathrm{C}$, respectively. It shows a good consistent tendency to the crystal size of samples. Particle sizes in SEM bigger than its crystal size of the corresponding sample are reasonable, since a particle in SEM is always composed by several crystals, not to mention the congregating of particles themselves.

It has been proved that the crystal structures and bond groups of phosphor materials show high dependence on the heat treatment or thermal annealing temperature [31]. An FTIR spectrometer is employed to test the effect of heat treatment temperature on the crystal structure of the $\operatorname{Pr}(\mathrm{III})$ doped $\mathrm{Y}_{2} \mathrm{SiO}_{5}$ upconversion nanomaterials, as shown in Figure 3. Sample calcined at $900^{\circ} \mathrm{C}$ shows two big absorption bands on the FTIR spectrum curve, in the range of 757$1048 \mathrm{~cm}^{-1}$ and $1260-1620 \mathrm{~cm}^{-1}$, which can be roughly identified to the vibration absorption of Si-O-Si bond and the bending vibration of $\mathrm{O}-\mathrm{H}$ bond, respectively. When heat treatment temperature is increased to $950^{\circ} \mathrm{C}$ or $1000^{\circ} \mathrm{C}$, both of the two absorption bands show a great change: the lower wavenumber absorption band splits into three absorption peaks, and the higher wavenumber absorption band disappears thoroughly.

High heat treatment temperature is believed to be beneficial to the forming of fine crystal structures of the nanomaterials. Therefore, as a result, when the upconversion nanomaterials are calcined at the temperature of $950^{\circ} \mathrm{C}$ and $1000^{\circ} \mathrm{C}$, the absorption band at $757-1048 \mathrm{~cm}^{-1}$ splits into three fine peaks at $849.7 \mathrm{~cm}^{-1}, 933.8 \mathrm{~cm}^{-1}$, and $1008.3 \mathrm{~cm}^{-1}$, which result from the bending vibration absorption of $\mathrm{Si}-\mathrm{O}$ bond, the symmetric vibration absorption of Si-O-Si bond, and the asymmetric vibration absorption of $\mathrm{Si}-\mathrm{O}-\mathrm{Si}$ bond, respectively, as curves (b) and (c) shown in Figure 3. It further demonstrates that samples calcined at $950^{\circ} \mathrm{C}$ have been converted 


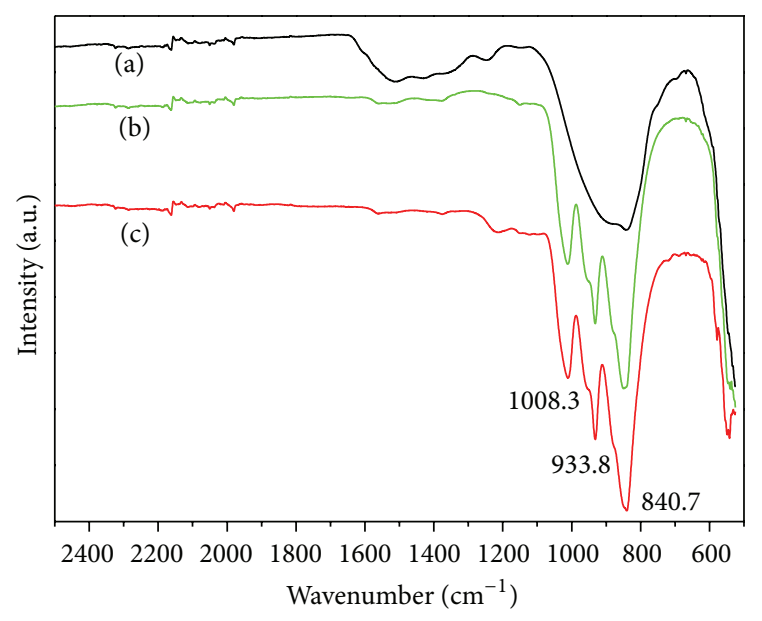

FIgURE 3: FTIR spectra of $\operatorname{Pr}($ III) doped samples calcined at different temperatures: (a) $900^{\circ} \mathrm{C}$, (b) $950^{\circ} \mathrm{C}$, (c) $1000^{\circ} \mathrm{C}$.

from amorphous state to crystal structure, which shows high consistency with the results of Figure 1.

The absorption bands at $1260-1620 \mathrm{~cm}^{-1}$ are attributed to the bending vibration of $\mathrm{O}-\mathrm{H}$ bond or $\mathrm{H}_{2} \mathrm{O}$, which is adsorbed on the internal holes surface of the nanomaterials or bonded with the nanomaterials in other forms. The bonded $\mathrm{H}_{2} \mathrm{O}$ in the materials is difficult to desorb at $900^{\circ} \mathrm{C}$. A higher heat treatment temperature is usually beneficial to the desorption of the bonded or adsorbed $\mathrm{H}_{2} \mathrm{O}$ in the materials, and lead to the disappearing of the absorption bands at 1260 $1620 \mathrm{~cm}^{-1}$ at the temperature of $950^{\circ} \mathrm{C}$ or $1000^{\circ} \mathrm{C}$, as curves (b) and (c) shown in Figure 3.

3.2. The Upconversion Luminescence of $Y_{2} \mathrm{SiO}_{5}$ Nanomaterials. Since the ionic radius of $\operatorname{Pr}(\mathrm{III})$ and $\mathrm{Y}(\mathrm{III}), 113 \mathrm{pm}$ and $104 \mathrm{pm}$, respectively, is very close [32], the lattice parameter of $\mathrm{Y}_{2} \mathrm{SiO}_{5}$ nanomaterials would not change a lot when $\operatorname{Pr}(\mathrm{III})$ dopes in and replaces the position of Y(III) in the lattice. Therefore, $\mathrm{X}$-ray diffraction patterns of $\mathrm{Y}_{2} \mathrm{SiO}_{5}$ upconversion nanomaterials show little dependence on the dope concentrations of $\operatorname{Pr}(\mathrm{III})$. However, the segregation of doped ions strongly modifies the luminescence properties of nanocrystals [33]. It means that the doping concentrations of $\operatorname{Pr}(\mathrm{III})$ play an important role on the upconversion luminescence of $\mathrm{Y}_{2} \mathrm{SiO}_{5}$ nanomaterials, as shown in Figure 4.

The blank sample, the sample without doped $\operatorname{Pr}(\mathrm{III})$, shows relative low luminescence intensity. On the other hand, those samples doped $\operatorname{Pr}(\mathrm{III})$ emit obvious luminescence spectra at the wavelength of $360 \mathrm{~nm}$. With the increasing of the dope concentration of $\operatorname{Pr}(\mathrm{III})$, the emission luminescence intensities are also enhanced obviously to a maximum of $6.43 \times 10^{6} \mathrm{cps}$ (count per second) with the $\operatorname{Pr}(\mathrm{III})$ doping concentration of $0.96 \%$. It shows an excellent enhancement of $\mathrm{Pr}(\mathrm{III})$ doping for the emission luminescence of $\mathrm{Y}_{2} \mathrm{SiO}_{5}$ nanomaterials. However, further increasing of $\operatorname{Pr}(\mathrm{III})$ doping concentration leads to a sharp decrease of the emission luminescence intensity. It is believed that too high of doping

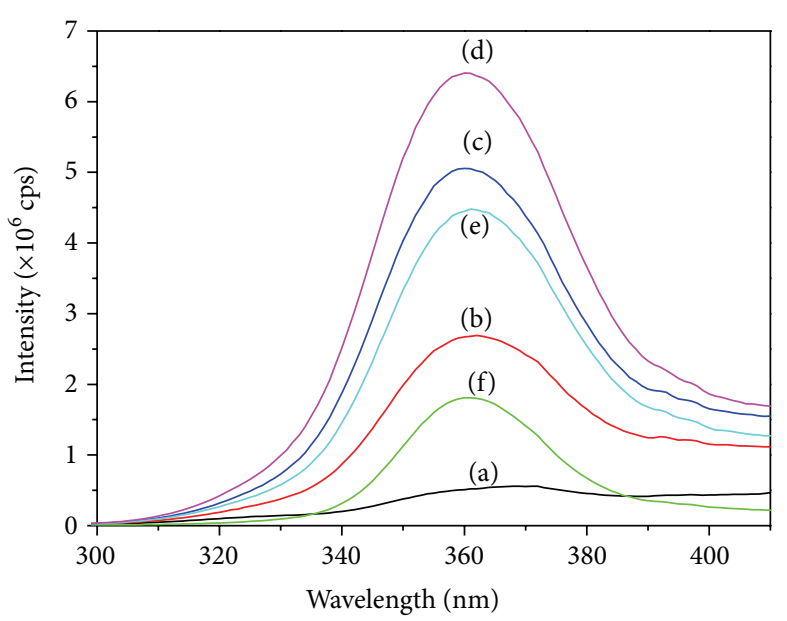

Peak values:
(a) $0.57 \times 10^{6} \mathrm{cps}$
(b) $2.67 \times 10^{6} \mathrm{cps}$
(c) $5.06 \times 10^{6} \mathrm{cps}$
(d) $6.43 \times 10^{6} \mathrm{cps}$
(e) $4.49 \times 10^{6} \mathrm{cps}$
(f) $1.83 \times 10^{6} \mathrm{cps}$

FIgURE 4: Emission spectra of $\mathrm{Y}_{2} \mathrm{SiO}_{5}$ doped different concentrations: of $\operatorname{Pr}(\mathrm{III})$, (a) $0.0 \%$, (b) $0.47 \%$, (c) $0.77 \%$, (d) $0.96 \%$, (e) $2.95 \%$ and (f) $4.93 \%$.

concentration of $\operatorname{Pr}(\mathrm{III})$ would result in luminescent quenching [34]. As a result, the highest doping concentration of 4.93\% $\operatorname{Pr}$ (III) results in the lowest luminescence intensity, $1.83 \times 10^{6} \mathrm{cps}$, of all the samples except for the blank sample, as shown in Figure 4.

3.3. Photodegradation of Nitrobenzene Wastewater. As a typical environmental priority control pollutant, nitrobenzene wastewater usually comes from the factories manufacturing medicines, pesticides, plastics, explosives. It is difficult to degrade by normal methods because of its particular molecular structures [35]. In this study, $10 \mathrm{mg} / \mathrm{L}$ nitrobenzene wastewater is used to test the photodegradation performances of $\mathrm{Pr}(\mathrm{III})$ doped $\mathrm{Y}_{2} \mathrm{SiO}_{5}$ upconversion nanomaterials. The doping concentrations of $\operatorname{Pr}(\mathrm{III}), 0.47 \%, 0.96 \%, 4.93 \%$, and the degradation time, $1 \mathrm{~h}$ to $6.5 \mathrm{~h}$, have been taken into account to learn the degradation rate of nitrobenzene in the water, as shown in Figure 5.

Sample doped $0.96 \% \operatorname{Pr}(\mathrm{III})$ shows much higher photodegradation rate at all the time than the samples of the other two doping concentrations, $0.47 \%$ and $4.93 \%$. It can be concluded that higher luminescence emission sample, such as $\mathrm{Y}_{2} \mathrm{SiO}_{5}$ nanomaterials doped $0.96 \% \operatorname{Pr}(\mathrm{III})$ as shown in Figure 4, would show a higher photodegradation rate on the pollutant. Too much of doping concentration is not a benefit to the increasing of photodegradation rate. On the other hand, as the time expands, the degradation rates of all the upconversion nanometer samples are increasing obviously at different rate. It is interesting that the slops of the fitting lines show the same tendency with the degradation rates of the doping concentrations. That is to say, higher degradation rate of the sample is also corresponding to higher slop of fitting line and showing faster photodegradation on the nitrobenzene. 


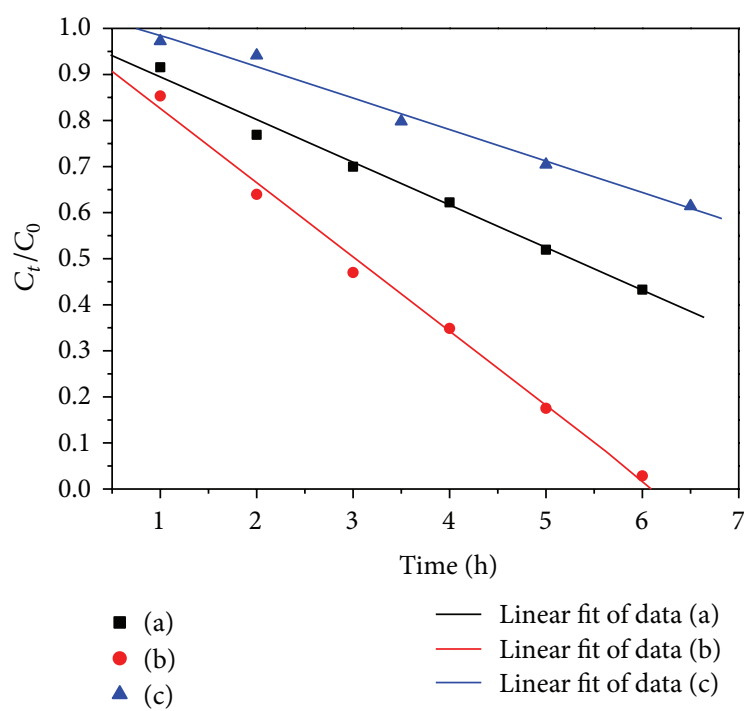

FIGURE 5: The photodegradation performances of $\operatorname{Pr}(\mathrm{III})$ doped $\mathrm{Y}_{2} \mathrm{SiO}_{5}$ nanomaterials (a) $0.47 \%$, (b) $0.96 \%$ and (c) $4.93 \%$.

First-order fitting of the $\ln \left(C_{0} / C\right)$ versus time for the photodegradation of pollutants, such as methyl orange and methylene blue, is usually used to study the reaction kinetics [36]. Based on the photodegradation rates of nitrobenzene with time, the photodegradation reaction kinetics lines are drawn out, as shown in Figure 6.

The best photodegradation belongs to the upconversion nanomaterials doped $0.96 \%$ of $\operatorname{Pr}(\mathrm{III})$, and too much of doping concentrations of $\operatorname{Pr}(\mathrm{III})$ would not show high photodegradation of upconversion nanomaterials, which confirms high consistency with the test results indicated in Figure 5. On the other hand, linear relationships appear between the degradation time and the value of $\ln \left(C_{t} / C_{0}\right)$, where $C_{t}$ is the concentration of nitrobenzene in the water at a time $(t)$ and $C_{0}$ is the original concentration of nitrobenzene $10 \mathrm{mg} / \mathrm{L}$, as shown in Figure 6. Each of the doping concentration of $\operatorname{Pr}(\mathrm{III}), 0.47 \%, 0.96 \%$, and $4.93 \%$, is according to a reaction kinetics linear equation and correlation indexes: $\ln C_{t} / C_{0}=-0.14399 t+0.05826, R=-0.99414, \ln C_{t} / C_{0}=$ $-0.29939 t+0.14481(t=1$ to $4 \mathrm{~h}), R=-0.99992$, and $\ln C_{t} / C_{0}=-0.08688 t+0.08227, R=-0.99486$, respectively. It can be concluded that the degradation reaction of nitrobenzene under the visible light follows the first-order kinetic law by the photodegradation of $\operatorname{Pr}(\mathrm{III})$ doped $\mathrm{Y}_{2} \mathrm{SiO}_{5}$ upconversion nanomaterials. However, as shown in Figure 6, the fit line for the sample doped $0.96 \% \mathrm{Pr}$ is linearly only at the first 4 hours. After that, the degradation reaction of nitrobenzene would not follow the first-order kinetics law.

\section{Conclusions}

Praseodymium ion, $\mathrm{Pr}(\mathrm{III})$, doped $\mathrm{Y}_{2} \mathrm{SiO}_{5}$ upconversion nanomaterials are prepared by using a sol-gel method. The doping concentrations of $\operatorname{Pr}(\mathrm{III})$ play important roles on the upconversion of the nanomaterials. The emission luminescence intensity of the nanomaterial reaches a maximum of

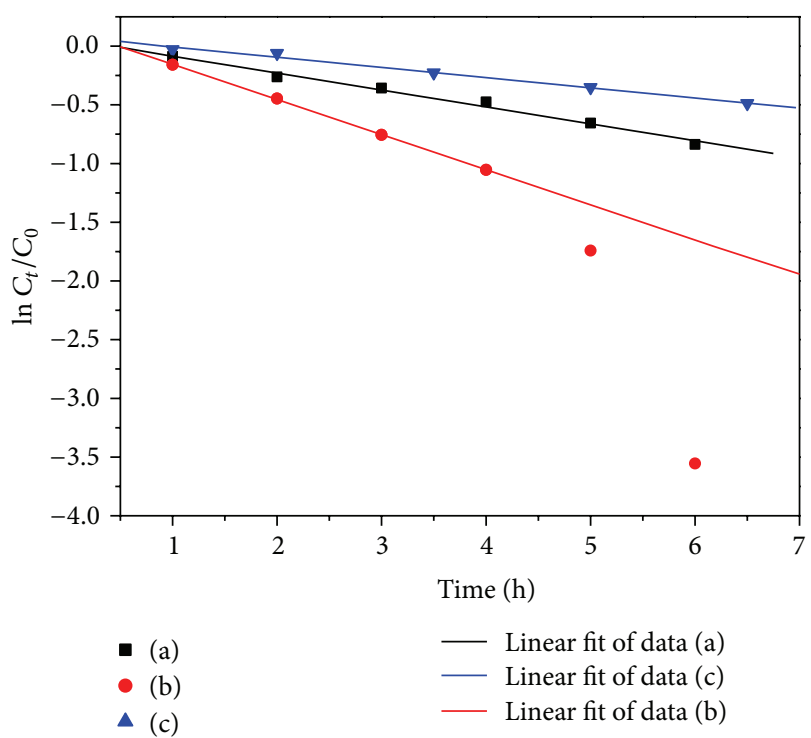

FIGURE 6: The photodegradation reaction kinetics data of nanomaterials (a) $0.47 \%$, (b) $0.96 \%$ and (c) $4.93 \%$.

$6.43 \times 10^{6}$ cps (count per second) with the $\operatorname{Pr}$ (III) doping concentration of $0.96 \%$. In addition, the optimized doping sample shows the best photodegradation performance in all the samples. For $10 \mathrm{mg} / \mathrm{L}$ of nitrobenzene wastewater, the photodegradation rate is up to $97.14 \%$ in 6 hours. The photodegradation reaction kinetics data indicated that the degradation reaction of nitrobenzene under the visible light follows the first-order kinetic law at the first 4 hours.

\section{Acknowledgment}

The work was supported by the Foundation of Jiangsu Environmental Protection Department, China (no. 2012015).

\section{References}

[1] Y. Sun, Y. Chen, L. Tian et al., "Controlled synthesis and morphology dependent upconversion luminescence of $\mathrm{NaYF}_{4}: \mathrm{Yb}$, Er nanocrystals," Nanotechnology, vol. 18, no. 27, Article ID 275609, 2007.

[2] J. Chen and J. X. Zhao, "Upconversion nanomaterials: synthesis, mechanism, and applications in sensing," Sensors, vol. 12, no. 3, pp. 2414-2435, 2012.

[3] C. Feldmann, T. Jüstel, C. R. Ronda, and P. J. Schmidt, "Inorganic luminescent materials: 100 Years of research and application," Advanced Functional Materials, vol. 13, no. 7, pp. 511-516, 2003.

[4] M. Kottaisamy, D. Jeyakumar, R. Jagannathan, and M. M. Rao, "Yttrium oxide: $\mathrm{Eu}^{3+}$ red phosphor by self-propagating high temperature synthesis," Materials Research Bulletin, vol. 31, no. 8, pp. 1013-1020, 1996.

[5] E. L. Cates, M. Cho, and J.-H. Kim, "Converting visible light into UVC: microbial inactivation by $\mathrm{Pr}^{3+}$-activated upconversion materials," Environmental Science and Technology, vol. 45, no. 8, pp. 3680-3686, 2011. 
[6] Q. Liu, Y. Sun, T. Yang, W. Feng, C. Li, and F. Li, "Sub-10 nm hexagonal lanthanide-doped $\mathrm{NaLuF}_{4}$ upconversion nanocrystals for sensitive bioimaging in vivo," Journal of the American Chemical Society, vol. 133, no. 43, pp. 17122-17125, 2011.

[7] C. Bouzigues, T. Gacoin, and A. Alexandrou, "Biological applications of rare-earth based nanoparticles," ACS Nano, vol. 5, no. 11, pp. 8488-8505, 2011.

[8] M. Wang, G. Abbineni, A. Clevenger, C. Mao, and S. Xu, "Upconversion nanoparticles: synthesis, surface modification and biological applications," Nanomedicine, vol. 7, no. 6, pp. 710729, 2011.

[9] Z. Li, L. Zheng, L. Zhang, and L. Xiong, "Synthesis, characterization and upconversion emission properties of the nanocrystals of $\mathrm{Yb}^{3+} / \mathrm{Er}^{3+}$-codoped $\mathrm{YF}_{3}$-YOF- $\mathrm{Y}_{2} \mathrm{O}_{3}$ system," Journal of Luminescence, vol. 126, no. 2, pp. 481-486, 2007.

[10] D. Yin, K. Song, Y. Ou, C. Wang, B. Liu, and M. Wu, "Synthesis of $\mathrm{NaYF}_{4}, \mathrm{NaLuF}_{4}$ and $\mathrm{NaGdF}_{4}$-based upconversion nanocrystals with hydro (solvo) thermal methods," Journal of Nanoscience and Nanotechnology, vol. 13, no. 6, pp. 4162-4167, 2013.

[11] H. Mi Noh, H. Kyoung Yang, B. Kee Moon, B. Chun Choi, J. Hyun Jeong, and H. Choi, "Concentration enhanced upconversion luminescence in $\mathrm{ZrO}_{2}: \mathrm{Ho}^{3+}, \mathrm{Yb}^{3+}$ nanophosphors," Journal of Nanoscience and Nanotechnology, vol. 13, pp. 4006-4009, 2013.

[12] G. Yi, Y. Peng, and Z. Gao, "Strong red-emitting near-infraredto-visible upconversion fluorescent nanoparticles," Chemistry of Materials, vol. 23, no. 11, pp. 2729-2734, 2011.

[13] J. Lin, Q. Su, H. Zhang, and S. Wang, "Crystal structure dependence of the luminescence of rare earth ions $\left(\mathrm{Ce}^{3+}, \mathrm{Tb}^{3+}\right.$, $\mathrm{Sm}^{3+}$ ) in $\mathrm{Y}_{2} \mathrm{SiO}_{5}$," Materials Research Bulletin, vol. 31, no. 2, pp. 189-196, 1996.

[14] T. Anh, P. Benalloul, C. Barthou, L. T. Giang, N. Vu, and L. Minh, "Luminescence, energy transfer, and upconversion mechanisms of $\mathrm{Y}_{2} \mathrm{O}_{3}$ nanomaterials doped with $\mathrm{Eu}^{3+}, \mathrm{Tb}^{3+}$, $\mathrm{Tm}^{3+}, \mathrm{Er}^{3+}$, and $\mathrm{Yb}^{3+}$ ions," Journal of Nanomaterials, vol. 2007, Article ID 48247, 10 pages, 2007.

[15] N. Nguyen, M. H. Nam, T. K. Anh, L. Q. Minh, and E. Tanguy, "Optical properties of $\mathrm{Eu}^{3+}$ doped $\mathrm{Y}_{2} \mathrm{O}_{3}$ nanophosphors," Advances in Natural Sciences, vol. 6, pp. 119-123, 2006.

[16] J. Lin, Q. Su, S. Wang, and H. Zhang, "Influence of crystal structure on the luminescence properties of bismuth (III), europium(III) and dysprosium(III) in $\mathrm{Y}_{2} \mathrm{SiO}_{5}$," Journal of Materials Chemistry, vol. 6, no. 2, pp. 265-269, 1996.

[17] H.-X. Mai, Y.-W. Zhang, L.-D. Sun, and C.-H. Yan, "Sizeand phase-controlled synthesis of monodisperse $\mathrm{NaYF}_{4}$ : $\mathrm{Yb}, \mathrm{Er}$ nanocrystals from a unique delayed nucleation pathway monitored with upconversion spectroscopy," Journal of Physical Chemistry C, vol. 111, no. 37, pp. 13730-13739, 2007.

[18] H.-X. Mai, Y.-W. Zhang, R. Si et al., "High-quality sodium rareearth fluoride nanocrystals: controlled synthesis and optical properties," Journal of the American Chemical Society, vol. 128, no. 19, pp. 6426-6436, 2006.

[19] J.-C. Boyer, L. A. Cuccia, and J. A. Capobianco, "Synthesis of colloidal upconverting $\mathrm{NaYF}_{4}: \mathrm{Er}^{3+} / \mathrm{Yb}^{3+}$ and $\mathrm{Tm}^{3+} / \mathrm{Yb}^{3+}$ monodisperse nanocrystals," Nano Letters, vol. 7, no. 3, pp. 847-852, 2007.

[20] G. Yi, B. Sun, F. Yang, D. Chen, Y. Zhou, and J. Cheng, "Synthesis and characterization of high-efficiency nanocrystal up-conversion phosphors: Ytterbium and erbium codoped lanthanum molybdate," Chemistry of Materials, vol. 14, no. 7, pp. 2910-2914, 2002.
[21] J.-H. Zeng, J. Su, Z.-H. Li, R.-X. Yan, and Y.-D. Li, “Synthesis and upconversion luminescence of hexagonal-phase $\mathrm{NaYF}_{4}: \mathrm{Yb}$, $\mathrm{Er}^{3+}$ phosphors of controlled size and morphology," Advanced Materials, vol. 17, no. 17, pp. 2119-2123, 2005.

[22] Y. Wei, F. Lu, X. Zhang, and D. Chen, "Synthesis of oildispersible hexagonal-phase and hexagonal-shaped $\mathrm{NaYF}_{4}$ : Yb,Er nanoplates," Chemistry of Materials, vol. 18, no. 24, pp. 5733-5737, 2006.

[23] G. H. Mhlongo, O. M. Ntwaeaborwa, M. S. Dhlamini, H. C. Swart, and K. T. Hillie, "Effects of $\mathrm{Ce}^{3+}$ concentration, beam voltage and current on the cathodoluminescence intensity of $\mathrm{SiO}_{2}: \mathrm{Pr}^{3+}-\mathrm{Ce}^{3+}$ nanophosphor," Journal of Alloys and Compounds, vol. 509, no. 6, pp. 2986-2992, 2011.

[24] K. Tan, H. Zhang, C. Xie, H. Zheng, Y. Gu, and W. F. Zhang, "Visible-light absorption and photocatalytic activity in molybdenum- and nitrogen-codoped $\mathrm{TiO}_{2}$," Catalysis Communications, vol. 11, no. 5, pp. 331-335, 2010.

[25] Y. V. Malyukin, A. A. Masalov, P. N. Zhmurin, N. V.Znamenskii, E. A. Petrenko, and T. G. Yukina, "Two mechanisms of ${ }^{1} \mathrm{D}_{2}$ fluorescence quenching of $\mathrm{Pr}^{3+}$-doped $\mathrm{Y}_{2} \mathrm{SiO}_{5}$ crystal," Physica Status Solidi (B) Basic Research, vol. 240, no. 3, pp. 655-662, 2003.

[26] A. Novoselov, H. Ogino, A. Yoshikawa et al., "Crystal growth, optical and luminescence properties of $\mathrm{Pr}$-doped $\mathrm{Y}_{2} \mathrm{SiO}_{5}$ single crystals," Optical Materials, vol. 29, no. 11, pp. 1381-1384, 2007.

[27] C. L. Sun, J. F. Li, C. H. Hu, H. M. Jiang, and Z. K. Jiang, "Ultraviolet upconversion in $\mathrm{Pr}^{3+}: \mathrm{Y}_{2} \mathrm{SiO}_{5}$ crystal by $\mathrm{Ar}^{+}$laser (488 nm) excitation," European Physical Journal D, vol. 39, no. 2, pp. 303306, 2006.

[28] S. F. Lim, R. Riehn, W. S. Ryu et al., "In vivo and scanning electron microscopy imaging of upconverting nanophosphors in Caenorhabditis elegans," Nano Letters, vol. 6, no. 2, pp. 169-174, 2006.

[29] L. Xiong, Z. Chen, Q. Tian, T. Cao, C. Xu, and F. Li, "High contrast upconversion luminescence targeted imaging in vivo using peptide-labeled nanophosphors," Analytical Chemistry, vol. 81, no. 21 , pp. 8687-8694, 2009.

[30] D. Cervantes-Vásquez, O.E. Contreras, and G.A. Hirata, “Quantum efficiency of silica-coated rare-earth doped yttrium silicate," Journal of Luminescence, vol. 143, pp. 226-232, 2013.

[31] M. K. Chong, K. Pita, and C. H. Kam, "Thermal annealing effect on $\mathrm{Y}_{2} \mathrm{O}_{3}: \mathrm{Eu}^{3+}$ phosphor films prepared by yttrium 2methoxyethoxide sol-gel precursor," Materials Chemistry and Physics, vol. 100, no. 2-3, pp. 329-332, 2006.

[32] T. H. Meen, H. D. Yang, W. J. Huang et al., "Ionic-size effect on the structure and $T_{c}$ of $T^{\prime}-\left(R_{1-x} R_{x}^{\prime}\right)_{1.85} \mathrm{Ce}_{0.15} \mathrm{CuO}_{4}(R=\mathrm{Pr}, \mathrm{Nd}$, Sm and Eu; $R^{\prime}=$ Gd and Y)," Physica C, vol. 260, no. 1-2, pp. 117$124,1996$.

[33] V. V. Seminko, A. A. Masalov, Y. I. Boyko, and Y. V. Malyukin, "Strong segregation of doped ions in $\mathrm{Y}_{2} \mathrm{SiO}_{5}: \mathrm{Pr}^{3+}$ nanocrystals," Journal of Luminescence, vol. 132, no. 9, pp. 2443-2446, 2012.

[34] L. Jia, Z. Shao, Q. Lü, Y. Tian, and J. Han, "Optimum europium doped aluminoborates phosphors and their photoluminescence properties under VUV and UV excitation," Optics \& Laser Technology, vol. 54, pp. 79-83, 2013.

[35] X. Fu, J. Ji, W. Tang, W. Liu, and S. Chen, "Mo-W based copper oxides: preparation, characterizations, and photocatalytic reduction of nitrobenzene," Materials Chemistry and Physics, vol. 141, no. 2-3, pp. 719-726, 2013.

[36] Y. Li, W. Wang, X. Qiu et al., "Comparing Cr, and N only doping with $(\mathrm{Cr}, \mathrm{N})$-codoping for enhancing visible light reactivity of $\mathrm{TiO}_{2}$," Applied Catalysis B, vol. 110, pp. 148-153, 2011. 

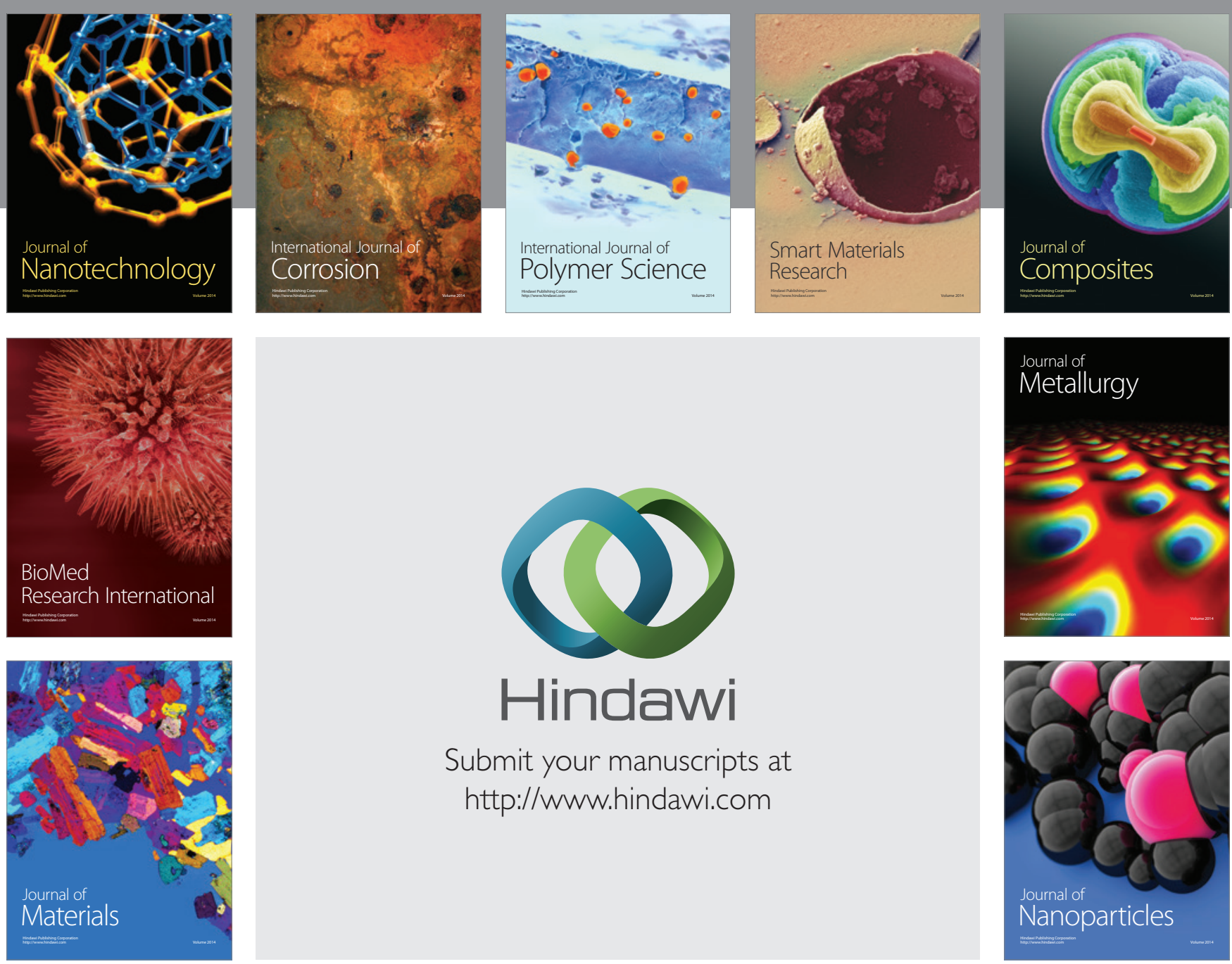

Submit your manuscripts at http://www.hindawi.com
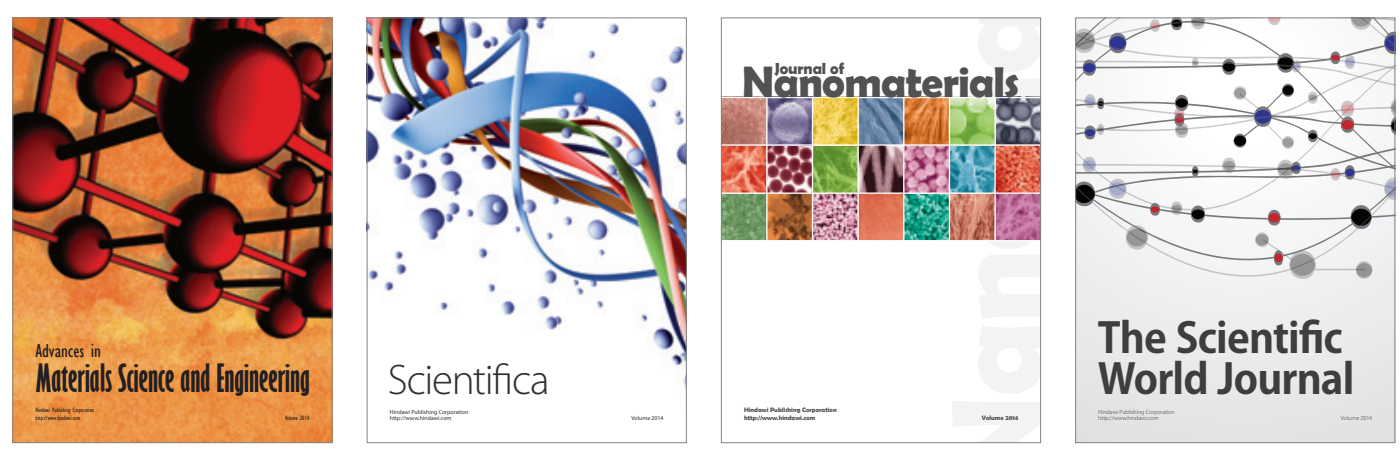

\section{The Scientific World Journal}
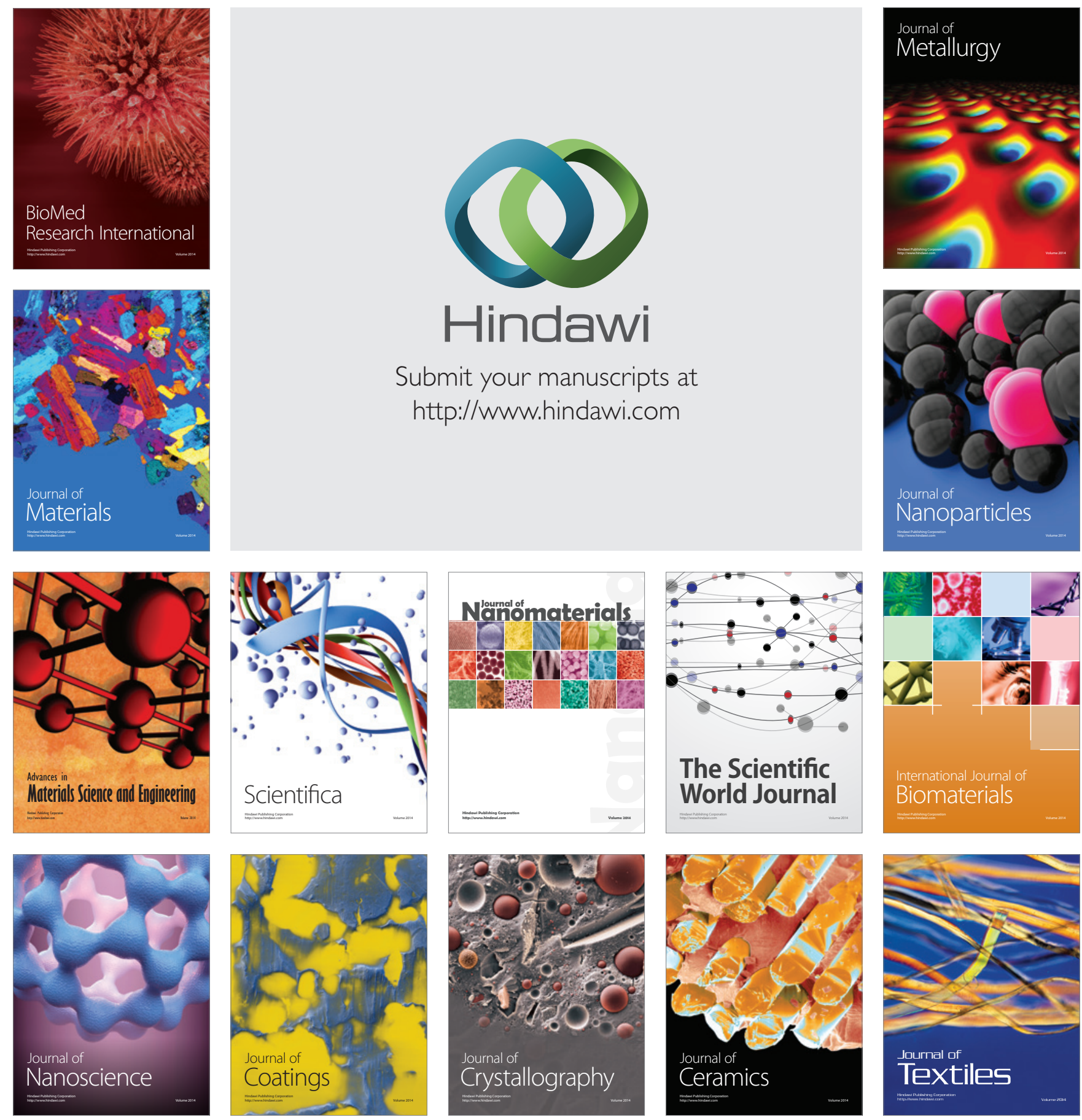